\title{
Analysis and exploration of infertility policies in Iran: a study protocol
}

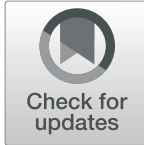

Bahar Morshed-Behbahani ${ }^{1}$, Minoor Lamyian ${ }^{*^{*}}$ D, Hassan Joulaei ${ }^{2}$ and Ali Montazeri ${ }^{3,4}$

\begin{abstract}
Background: Infertility is a complex and neglected reproductive health issue of global proportions, with varying effects on couples and their relationships. Therefore, international organisations and several countries have been compelled to consider infertility policies. In recent years, a shift in population policy trends toward increasing birth rates in Iran have set infertility policies in the health sector's agenda. Since infertility and its associated problems are multifactorial, all health systems, including that of Iran, need to have a comprehensive policy package that covers all of its dimensions. Policy analysis is necessary to formulate such policies. This project will therefore analyse the infertility policies in Iran's health sector and clarify the multilateral effects of their different components.

Methods: This multidisciplinary study outlines the conceptual framework of infertility policies and consists of three stages. Stage I will involve the review of infertility policies in selected countries and Iran for the operational model of infertility programmes, rules and policies. Stage II will consist of a documentary infertility policy analysis of Iran. At this stage, Iran's infertility policies will be analysed using the Walt and Gilson framework in four areas, namely content, context, process and actors. Stage III will involve the analysis of infertility policies in Iran. At this stage, a qualitative study will be conducted to understand and provide indepth explanations of the existing policies. Finally, the concepts and outcomes obtained from the first stage will be combined with the content of the qualitative analysis of the second and third stages for exploration of Iran's infertility policies, and a package including a framework for infertility policies will be proposed.

Discussion: The findings of this study can be used by the Ministry of Health and public health policy-makers to determine which policies, in view of socio-cultural and economic contexts and actors' roles in each country, can be used to reach the goals defined by international organisations, on the prevention of infertility and reproductive health.
\end{abstract}

Keywords: Infertility, policy analysis, Iran

\section{Background}

Infertility is a complex and neglected reproductive health issue worldwide [1]. Globally, more than 186 million people suffer from infertility [2], with various effects on couples and their relationships [3]. It evidently makes couples feel desperate, worried, indignant, inadequate, guilty and socially isolated. It is believed that the negative consequences of social exclusion due to infertility could lead to divorce, violence against women, shame and social suffering [4,

\footnotetext{
* Correspondence: lamyianm@modares.ac.ir

${ }^{1}$ Department of Reproductive Health and Midwifery, Faculty of Medical

Sciences, Tarbiat Modares University, Tehran, Iran

Full list of author information is available at the end of the article
}

5]. In addition, in many countries, infertility treatment poses an extra burden to couples and families $[6,7]$. As such, WHO recommended to its country members the establishment of policies for infertility treatment [8] and, in a report, asked that health systems gradually shift from therapeutic management to prevention as needed [9]. Indeed, the Human Reproduction Programme developed new guidelines for infertility care to help developing countries integrate policies into existing services, systems and reproductive health programmes [10].

An assessment of existing policies for infertility in different countries highlights that the oldest guidelines belong to the United Kingdom and the United States of 
the America. In the United Kingdom, the related services, costs and insurance have been codified in the $\mathrm{Na}$ tional Health Services. The protocols, rules and guidelines are evaluated and reviewed annually by the National Institute for Health and Care Excellence [1113]. In the United States, the American Society for Reproductive Medicine, the United States Department of Health and Human Services, and the Center for Disease Control and Prevention also formulated the required policies and guidelines and defined infertility services at three levels - early assessment, prevention, and early and specialised treatment [14-17].

The prevalence of infertility in Iran ranges from $10.3 \%$ to $24.9 \%[18,19]$. Similar to any other country, complications of infertility for Iranian couples include psychological distress [20] and social suffering [3, 21]. Unfortunately, financial problems, such as expensive treatments and lack of insurance coverage, are the major worries of infertile couples [3] and thus treatment drop-out in Iran is as high as $28.3 \%$ [22].

The abovementioned reasons, on the one hand, and shifting in population policy in order to increase birth rate in Iran [23], on the other, have been sufficient to set infertility policies within the agenda in recent years in the health system of Iran.

To the best of our knowledge, current policies for infertility in Iran are incoherent, exclusively therapeutic [7] and distributive [24]. These policies have led to the establishment of public and private healthcare centres with inappropriate distribution [1]. Other infertility policies were developed with the goal of encouraging and increasing fertility replacement levels. However, these caused financial difficulties in the provision of drugs and infertility treatment for all infertile couples, regardless of their financial condition [7]. These policies did not address issues such as prevention, early diagnostic and referral processes, primary and supportive treatments, and accessibility of infertility services. Even in the latest healthcare reform plan infertility services have not been included.

Since infertility and its associated problems are multifactorial in nature, so all health systems, including that of Iran, need to have a comprehensive policy package that covers all of its dimensions. To formulate such policies, a through policy analysis is necessary. Indeed, policy analysis will help to examine the role of four elements - actors, process, context and content. Such analysis might specify and predict the causes of the success or challenge, barriers or facilitators of policies, and required planning to improve them [25]. In this regard, it is important to know how these four factors affect the infertility policies and how they have been successfully implemented.

Therefore, this study is designed to analyse the infertility policies in Iran's health sector and clarify the multilateral effects of different components of these policies, including content, context, process and actors on running these policies. Since infertility policies are either new or an ongoing process in most countries, this study might contribute to existing knowledge on the topic and help policy-makers in order to formulate a plan in health systems.

\section{Objectives}

The main goal of this study, which is planned to last 2 years, is to analyse and explore infertility policies in Iran's health system. Analysis will cover prevention, diagnosis, timely treatment and supportive policies, while exploration will focus on proposing the required policies. Thus, the objectives are indicated as follows:

1. To review and compare infertility programmes in Iran and other countries.

2. To analyse existing policies for infertility in Iran.

3. To propose a holistic package of prevention, therapeutic and supportive infertility policies for Iran.

\section{Methods/Design}

This multidisciplinary study outlines the conceptual framework of infertility policies and consists of the following three stages.

\section{Stage I: Review of infertility services policy in selected countries and Iran}

In this stage, a systematic literature review on infertility policies guided by the Preferred Reporting Items for Systematic Reviews and Meta-analyses (PRISMA) will be performed [26].

\section{Definition}

The policy documents will be defined as all formal records and reports that were written by national governments, national scientific communities and academic societies, national authorities and international organisations' decisions, reports, plans and actions from WHO or World Bank, world health statistics, world development indicators, and demographic and health surveys. The type of evidence will include provincial annual reports, core public health function/standards documents, health human resources, human resource planning annual reports, business plans, commissioning policy documents, clinical guidelines, health profession legislation, and other public health reports such as competency development and leadership frameworks.

\section{Search engines and time period}

Documents will be selected from 1994 (since the Cairo Conference) until the end of 2018. The Cairo 
Conference recommended countries to plan and implement action to prevent and treat infertility [27]. The search engines will include PubMed, ISI, Google Scholar, all public websites, websites of health ministries, and websites of infertility clinics searching for review articles, grey papers, government records and guidelines, protocols, and clinical guidelines.

\section{Search strategy}

The search strategy will include a combination of the keywords 'infertility', 'policy-making', 'affordability', 'availability', 'acceptability', 'awareness', 'responsibilities', 'insurance', 'health policy', 'prevention', 'financial management', 'childlessness', 'equity', 'utilization' and 'cost'.

\section{Inclusion and exclusion criteria}

Documents in English language that address the operational model of infertility programmes, rules and policies will be included. The main focus at this stage will be on infertility policies, executive processes and prevention or implementation of policies in providing fair services at three levels (prevention, early treatment and supportive care). Irrelevant documents will be excluded. For instance, discussion papers, advertisements, video clips, newspapers, online advertising sites, movie content, and marketing channels will not be included.

\section{Selection of countries}

The selection of countries will be based on the availability of appropriate documents and existence of comprehensive infertility policy from all five continents and from all income groups (high, middle and low) with the help of the expert panel and the research team.

\section{Data extraction and synthesis}

First, a datasheet for each country will be prepared including the following information: name and aim of the policy, author(s) or organisation name and actors involved; this information will be tabulated and made ready for further analysis (Table 1). We will then identify three components for each policy document as defined by universal health coverage, as follows: (1) financial protection, (2) population coverage, and (3) service package, including services for prevention, treatment and supportive care [28]. The indicators and practical definition of policy components were provided and were finalised in two sessions by an expert panel consisting of two specialists in health policy, two public health scientists, a gynaecologist and a reproductive health specialist. These explanatory variables and indicators are described in Table 2. The findings will be then be scored; for each component, if the policy satisfies the condition, a score of 3 will be assigned, otherwise, a score of 2 (intermediate) or 1 (low) will be considered (Table 3). Finally, a scoring sheet containing scores for all countries, including Iran, will be provided and compared. A hypothetical scoring sheet is provided in Table 4 .

\section{Stage II: Documentary analysis of Iranian infertility policies}

During this stage, a review of the actual published policies and guideline documents in Iran will be carried out [29, 30]. As such, we will use the content analysis. It is suitable for exploring rationales, strengths and weaknesses of the infertility policies [31, 32]. This will help us to analyse content, context, process, and actors that are prominent or have a role in these policies. We will code all the data that extracted at stage I, and the rest of the documents related to the infertility care policies in Persian language. Thematic analysis will then be conducted and categorised based on the Walt and Gilson framework [33].

\section{Stage III: Infertility policy analysis of Iran}

At this stage, Iran's infertility policies will be analysed using the Walt and Gilson framework in four areas, namely content, context, process and actors. Infertility policies can include different rules, framework actions to achieve specific goals, action plans, tasks, or an unwritten ethical or cultural code that guides behaviour. Each culture and social context will have different and proprietary health policies. The policies are developed in a variety of ways and have different executive formation processes influenced by different people with different actions [34]. Therefore, all of these will be considered in the policy analysis and exploration of the new infertility policies. In this way, we will achieve the second goal of the study. Thus, a qualitative study will be conducted to understand and provide in-depth explanations of the existing policies.

\section{Data sources and sampling}

Participants in this section include experienced/most informed experts, including policy-makers and decision-makers involved in fertility and infertility health programmes at the Ministry of Health, and

Table 1 A schematic view of summary of each country's profile

\begin{tabular}{llllll}
\hline Country & Title & Year & Name of the policy & Aim(s) of the policy & Author(s) or organisation name
\end{tabular}


Table 2 Definitions of dependent and explanatory variables

\begin{tabular}{|c|c|}
\hline Variable & Measure \\
\hline \multicolumn{2}{|l|}{ Financial protection } \\
\hline Insurance coverage & $\begin{array}{l}\text { The amount of risk or liability that is covered for an individual or entity by way of insurance } \\
\text { infertility services }\end{array}$ \\
\hline Government funding & Money provided by the government to pay for infertility services \\
\hline Supply of voluntary and charitable donations & Financial support from voluntary associations or non-governmental organs \\
\hline \multicolumn{2}{|l|}{ Population coverage } \\
\hline Gender & Gender sensitivity in the service delivery ${ }^{*}$ \\
\hline Age & Availability of services for all age \\
\hline Urban/rural coverage & Availability of infertility services in urban and rural areas \\
\hline \multicolumn{2}{|l|}{ Service package } \\
\hline Acceptability & Cultural, social and religious acceptance of infertility services \\
\hline Accessibility/availability & $\begin{array}{l}\text { Considering the number of service centres in relation to the population and their } \\
\text { distribution }\end{array}$ \\
\hline Awareness/registry & Having proper registry system \\
\hline Preventive & $\begin{array}{l}\text { Existence of a preventive service, which includes check-ups, patient counselling and } \\
\text { screenings to prevent infertility }\end{array}$ \\
\hline Diagnostic and curative & Providing all infertility diagnostic and curative services \\
\hline Rehabilitation, and supportive care & $\begin{array}{l}\text { Existing rehabilitative infertility care includes empowerment of the couples to manage } \\
\text { their conditions with proper counselling and enabling them to enjoy life by appropriate } \\
\text { rules for adoption }\end{array}$ \\
\hline
\end{tabular}

* 1. Availability of infertility services to single women or men ,widows, and homosexual. 2. Equal treatment (e.g.,waiting time,courtesy, privacy, information given) for male and female clients

stakeholders including heads of hospitals, insurance agencies, infertility specialists and infertile couples. To select participants, the purposive sampling method and a maximum diversity approach will be used. Inclusion criteria are the job position, the knowledge and awareness, and the sufficient motivation to collaborate in the research. Individual semi-structured interviews will be used to produce data. The interviews will be based on the study objectives. Sampling will continue until data saturation.

\section{Rigor}

To ensure validity and reliability, the research team will compare and review the initial codes frequently with the initial summaries of the data. The codes will then be

Table 3 Indicators that will be used for scoring

\begin{tabular}{|c|c|c|c|}
\hline Score & 1 (Low) & 2 (Intermediate) & 3 (Good) \\
\hline \multicolumn{4}{|l|}{ Financial protection } \\
\hline $\begin{array}{l}\text { Insurance coverage/government funding/supply of voluntary and } \\
\text { charitable donations }\end{array}$ & One of the items & Two of the items & All three items \\
\hline \multicolumn{4}{|l|}{ Population coverage } \\
\hline Gender & Only for female or male & $\begin{array}{l}\text { Married female and } \\
\text { male }\end{array}$ & All \\
\hline Age & Limited & Reproductive age period & Not limited \\
\hline Urban/rural coverage & $\begin{array}{l}\text { Urban only without rural } \\
\text { access }\end{array}$ & $\begin{array}{l}\text { Urban with difficult rural } \\
\text { access }\end{array}$ & $\begin{array}{l}\text { Urban with good rural } \\
\text { access }\end{array}$ \\
\hline \multicolumn{4}{|l|}{ Service package } \\
\hline Acceptability & Low & Moderate & High \\
\hline Accessibility/availability & Low & Moderate & High \\
\hline Registry & Low & Moderate & High \\
\hline Preventive services & Lack of policy & Poor policies & Efficient policies \\
\hline Diagnostic and curative services & Lack of policy & Poor policies & Efficient policies \\
\hline Rehabilitation and supportive care services & Lack of policy & Poor policies & Efficient policies \\
\hline
\end{tabular}


Table 4 Scoring sheet for infertility policy based on universal health coverage framework

\begin{tabular}{|c|c|c|c|c|c|c|}
\hline \multirow{2}{*}{$\frac{\text { Economic situation }}{\text { Country }}$} & \multicolumn{2}{|c|}{ Low income } & \multicolumn{2}{|c|}{ Middle income } & \multicolumn{2}{|c|}{ High income } \\
\hline & a & $b$ & c & $d$ & e & $f$ \\
\hline \multicolumn{7}{|l|}{ Financial protection } \\
\hline \multicolumn{7}{|c|}{ Insurance coverage/Government funding/supply of voluntary and charitable donations } \\
\hline \multicolumn{7}{|l|}{ Population coverage } \\
\hline \multicolumn{7}{|l|}{ Gender } \\
\hline \multicolumn{7}{|l|}{ Age } \\
\hline \multicolumn{7}{|l|}{ Urban/rural coverage } \\
\hline \multicolumn{7}{|l|}{ Service package } \\
\hline \multicolumn{7}{|l|}{ Acceptability } \\
\hline \multicolumn{7}{|l|}{ Accessibility/availability } \\
\hline \multicolumn{7}{|l|}{ Registry } \\
\hline \multicolumn{7}{|l|}{ Preventive services } \\
\hline \multicolumn{7}{|l|}{ Diagnostic and Curative services } \\
\hline \multicolumn{7}{|l|}{ Rehabilitation and supportive care services } \\
\hline Total score* & & & & & & \\
\hline
\end{tabular}

* Total score can range from 10 (least) to 30 (highest)

provided to the participants in order to be validated. To ensure the validity and reliability of the data, the four criteria of Lincoln and Guba will be used [35].

\section{Analysis}

Following interviews, coding and analysis will be carried out manually with the framework analysis. This is a qualitative method that is aptly suited for applied social policy research and is currently used for health policy studies. It is adapted to research that has specific questions, a pre-designed sample and a priori issues [36].

\section{Exploration}

In this stage, the policies resulting from the first stage will be integrated with the findings from qualitative content analysis in the second and third stages to synthesise a comprehensive proposed model for infertility prevention and care in Iran by the expert panel. The probable integration model of stages and hypothetical conditions are shown in Table 5 [37].

\section{Discussion}

Findings from this policy analysis will underline the complex nature of the policy-making process and the multiple influences and actors over this process. This analysis will be organised around a description of gaps or confirmation of desirable infertility policies in selected countries and national policies in Iran. Findings from this study will contribute to an understanding of the complexities in the roles of actors on the process of policy-making and implementation of policy with considerable social, cultural and health system challenges. This study will improve decision-makers' insight into the importance of the underlying factors in the formulation of policies, the stakeholders' contribution to creating a policy prioritisation process, and the state of evidence and documentation in decision-making and policy innovation. The results of this study will also clarify how and why some evidence affects the flow of decisionmaking regarding fertility programmes and why some problems persist [38]. Increasing understanding of the role of facilitators and barriers to implementing infertility policies for decision-makers, in turn, can lead to the development of processes for accelerating and maximising expected results [39]. Using this method and developing the concepts of the theoretical part based on qualitative procedures, this study will provide new knowledge about the type and quality of evidence, thus providing the necessary evidence to change the perspective of different decision-makers. This change of

Table 5 Hypothetical conditions

\begin{tabular}{llll}
\hline & Finding from stage 1 & Finding from stages 2 and 3 & Expected results \\
\hline Condition 1 & Policy achievements & The same achievements & Confirmation \\
Condition 2 & Policy achievements & No achievement & Need for development and customisation of policies \\
Condition 3 & No achievement & Achieved policies & Improvement and standardisation of policies \\
\hline
\end{tabular}


perspective includes groups or contexts that may normally be less variable, such as medical professionals [40], or may be appropriate where there is a need to make major changes to multiple systems involving multiple organisations and/or different stakeholders.

The findings of this study can be used by national health policy-makers to determine which policies, in view of political, socio-cultural and economic contexts, can be applied to reach the goals defined by international organisations to improve the prevention and care of infertility programmes in Iran. Additionally, exploration of prevention policies and determining the pathway for the referral and treatment of infertile couples can improve reproductive health in at-risk individuals and promote their mental health, social and family status, as well as reducing the catastrophic costs due to infertility care.

\section{Acknowledgements}

This study is part of the PhD thesis of the first investigator at the Department of Reproductive Health and Midwifery, Faculty of Medical Science, Tarbiat Modares University, Tehran, Iran.

\section{Authors' contributions}

$\mathrm{BMB}$ was the main investigator, designed the study and wrote the first draft. ML supervised the study, provided key information and contributed to the writing process. HJ was the study advisor, provided background information and helped with the methodology. AM was the study advisor, critically reviewed the manuscript and provided the final draft. All authors read and approved the manuscript.

\section{Funding}

None.

\section{Availability of data and materials}

The data will be available on reasonable request from the corresponding author in due course.

\section{Ethics approval and consent to participate}

The ethics committee of Tarbiat Modares University (TMU) approved the study (ethics code: IR.TMU.REC.1396.701). A written informed consent form will be completed for all participants.

\section{Consent for publication}

Not applicable.

\section{Competing interests}

The authors declare that they have no competing interests.

\section{Author details}

${ }^{1}$ Department of Reproductive Health and Midwifery, Faculty of Medical Sciences, Tarbiat Modares University, Tehran, Iran. ${ }^{2}$ Health Policy Research Center, Institute of Health, Shiraz University of Medical Sciences, Shiraz, Iran. ${ }^{3}$ Population Health Research Group, Health Metrics Research Center, Institute for Health Sciences Research, ACECR, Tehran, Iran. ${ }^{4}$ Faculty of Humanity Sciences, University of Sciences \& Culture, ACECR, Tehran, Iran.

Received: 3 March 2019 Accepted: 7 November 2019

Published online: 15 January 2020

\section{References}

1. Zuccala E, Horton R. Addressing the unfinished agenda on sexual and reproductive health and rights in the SDG era. Lancet. 2018;391(10140): 2581-3.
2. Vahidi S, Ardalan A, Mohammad K. Prevalence of primary infertility in the Islamic Republic of Iran in 2004-2005. Asia Pac J Public Health. 2009;21(3): 287-93.

3. Morshed-Behbahani B, Mossalanejad L, Shahsavari S, Dastpak M. The experiences of infertile women on assistant reproductive treatments: a phenomenological study. Iran Red Crescent Med J. 2012;14(6):382-3.

4. Greil AL, Slauson-Blevins K, McQuillan J. The experience of infertility: a review of recent literature. Sociol Health IIIn. 2010;32(1):140-62.

5. Daniels J. Infertility, Key Issues, Continuum of Care. Geneva: World Health Organization; 2014. http://www.who.int/reproductivehealth/topics/infertility/ keyissues/en. Accessed 15 Feb 2019.

6. Dyer SJ, Sherwood K, McIntyre D, Ataguba JE. Catastrophic payment for assisted reproduction techniques with conventional ovarian stimulation in the public health sector of South Africa: frequency and coping strategies. Hum Reprod. 2013;28(10):2755-64.

7. Tremayne S, Akhondi MM. Conceiving IVF in Iran. Reprod Biomed Soc Online. 2016:2:62-70.

8. World Health Organization. Preconception Care: Maximizing the Gains for Maternal and Child Health. Geneva: World Health Organization; 2013. p. 8.

9. van der Poel SZ. Historical Walk: The HRP Special Programme and Infertility. Gynecol Obstet Investig. 2012;74(3):218-27.

10. HRP Annual Report 2016. WHO Document Production Services. Geneva: World Health Organization; 2017.

11. Ann K. Evidence Review: Reproductive Health. Population Health and Wellness BC Ministry of Health. Victoria: BC Ministry of Health; 2008.

12. Cleary-Gray W, Martin J. Beckett V, Brown H, Cutting R, Edward C. Access to Infertility Treatment: Commissioning Policy Document Yorkshire and Humber. Leeds: NHS; 2013.

13. Wilde R, Brian K, Rayfield LB, Rutherford A, Khalaf Y. Business Plan: Authority Meeting Agenda. London: HFEA; 2017.

14. Ethics Committee of the American Society for Reproductive Medicine. Disparities in access to effective treatment for infertility in the United States: an Ethics Committee opinion. Fertil Steril. 2015;104(5):1104-10.

15. Kessler LM, Craig BM, Plosker SM, Reed DR, Quinn GP. Infertility evaluation and treatment among women in the united states. Fertil Steril. 2013;100(4): 1025-32. https://doi.org/10.1016/j.fertnstert.2013.05.040.

16. Warner L, Adashi YE, Collura B. Public Health Grand Rounds: Time for Public Health Action on Infertility. Atlanta: CDC; 2014

17. Richie $\mathrm{C}$. Reading between the lines: infertility and current health insurance policies in the US. Clin Ethics. 2014;9(4):127-34.

18. Parsanezhad ME, Jahromi BN, Zare N, Keramati P, Parsa-Nezhad M, Khalili A. Epidemiology and etiology of infertility in Iran, systematic review and metaanalysis. J Womens Health Issues Care. 2013;2(6). https://doi.org/10.4172/ 2325-9795.1000121.

19. Inhorn MC, Patrizio P. Infertility around the globe: new thinking on gender, reproductive technologies and global movements in the 21 st century. Hum Reprod Update. 2015;21(4):411-26.

20. Karimzadeh M, Salsabili N, Akbari Asbagh F, Teymouri R, Pourmand G, Soleimanieh NT. Psychological disorders among Iranian infertile couples undergoing assisted reproductive technology (ART). Iran J Public Health. 2017:46(3):333-41

21. Hasanpoor-Azghdy SB, Simbar M, Vedadhir A. The social consequences of infertility among Iranian women: a qualitative study. Int J Fertil Steril. 2015; 8(4):409-20.

22. Khalili MA, Kahraman S, Ugur MG, Agha-Rahimi A, Tabibnejad N. Follow up of infertile patients after failed ART cycles: a preliminary report from Iran and Turkey. Eur J Obstet Gynecol Reprod Biol. 2012;161(1):38-41.

23. Karamouzian $M$, Haghdoost AA. Population control policies in Iran. Lancet. 2015:385(9973):1071

24. Lowi TJ. American Business, Public Policy, Case-Studies, and Political Theory. World Polit. 2011;16(4):677-715

25. El-Jardali F, Bou-Karroum L, Ataya N, El-Ghali HA, Hammoud R. A retrospective health policy analysis of the development and implementation of the voluntary health insurance system in Lebanon: Learning from failure. Soc Sci Med. 2014;123(Supplement C):45-54.

26. Stroup DF, Berlin JA, Morton SC, Olkin I, Williamson GD, Rennie D, et al. Meta-analysis of observational studies in epidemiology: a proposal for reporting. Meta-analysis Of Observational Studies in Epidemiology (MOOSE) group. JAMA. 2000;283(15):2008-12.

27. UNFPA. Program of Action, International Conference on Population and Development (ICPD). Cairo Geneva: United Nations; 1994. 
28. World Health Organization. The World Health Report: Health Systems Financing: The Path to Universal Coverage. Geneva: World Health Organization; 2010.

29. Hanney S, Block MA, Buxton M, Kogan M. The utilisation of health research in policy-making: concepts, examples and methods of assessment. Health Res Policy Syst. 2003;1:2.

30. Duffy J, Rolph R, Gale C, Hirsch M, Khan K, Ziebland S, et al. Core outcome sets in women's and newborn health: a systematic review. BJOG Int J Obstet Gynaecol. 2017;124(10):1481-9.

31. Hsieh HF, Shannon SE. Three approaches to qualitative content analysis. Qual Health Res. 2005;15(9):1277-88.

32. Finfgeld-Connett D. Use of content analysis to conduct knowledge-building and theory-generating qualitative systematic reviews. Qual Res. 2014;14(3):341-52.

33. Walt G, Gilson L. Reforming the health sector in developing countries: the central role of policy analysis. Health Policy Plann. 1994;9:353-70.

34. Lehmann U. Master's in Public Health: Understanding and Analyzing Health Policy Module Guide. South Africa: School of Public Health, University of the Western Cape; 2016.

35. Lincoln YS, Guba EG. Naturalistic Inquiry. London: Beverley Hills CA Sage; 1985.

36. Ritchie J, Spencer L. Qualitative data analysis for applied policy research by J Ritchie and L Spencer. In: Bryman A, Burgess RG, editors. Analysing Qualitative Data. London: Routledge; 1994. p. 173-94.

37. Whittingham C, Hoffman E. The collaborative choice matrix: a tool for dialogic data-driven decision making. III Read Counc J. 2016:44:14-9.

38. Sumner A, Crichton J, Theobald S, Zulu E, Parkhurst J. What shapes research impact on policy? Understanding research uptake in sexual and reproductive health policy processes in resource poor contexts. Health Res Policy Syst. 2011;9(1):S3.

39. Koduah A, van Dijk H, Agyepong IA. The role of policy actors and contextual factors in policy agenda setting and formulation: maternal fee exemption policies in Ghana over four and a half decades. Health Res Policy Syst. 2015;13:27.

40. Timmermans $\mathrm{S}$, Oh H. The continued social transformation of the medical profession. J Health Soc Behav. 2010;51(Suppl):S94-106.

\section{Publisher's Note}

Springer Nature remains neutral with regard to jurisdictional claims in published maps and institutional affiliations.

Ready to submit your research? Choose BMC and benefit from:

- fast, convenient online submission

- thorough peer review by experienced researchers in your field

- rapid publication on acceptance

- support for research data, including large and complex data types

- gold Open Access which fosters wider collaboration and increased citations

- maximum visibility for your research: over $100 \mathrm{M}$ website views per year

At BMC, research is always in progress.

Learn more biomedcentral.com/submissions 